\title{
Clinical significance of clusterin expression in pancreatic adenocarcinoma
}

\author{
Junshuo Jin ${ }^{1}$, Joon-Mee Kim², Yoon-Seok Hur ${ }^{3}$, Won Pyo Cho ${ }^{3}$, Keon-Young Lee ${ }^{3 *}$, Seung-lk Ahn ${ }^{3}$, Kee Chun Hong ${ }^{3}$ \\ and In-Sun Park ${ }^{4}$
}

\begin{abstract}
Background: Clusterin is known to be expressed in many human neoplasms, and is believed to participate in the regeneration, migration, and anti-apoptosis of tumor cells. However, few reports have addressed the relationship between the manifestation of clusterin and clinicopathologic parameters in pancreas cancer patients. In the present study, the authors investigated the expression of clusterin and its clinical significance in pancreatic adenocarcinoma.

Methods: Immunohistochemical staining was performed for clusterin in tumor tissues obtained from patients who received pancreatic resection with radical intent, and the associations of clusterin expression with various clinicopathologic parameters were analyzed in addition to the relation between its expression and survival.

Results: Immunoreactivity for clusterin was observed in 17 of the 52 (33\%) pancreatic adenocarcinomas examined. In addition, clusterin positivity was found to be associated with preoperative serum carcinoembryonic antigen level, perineural invasion, and, most strongly, lymph node metastasis. The survival analysis identified tumor differentiation and lymph node metastasis as the only significant prognostic factors.
\end{abstract}

Conclusion: Although not an independent prognostic factor, clusterin immunoreactivity can be used in conjunction with lymph node metastasis to predict survival in cases of pancreatic adenocarcinoma.

Keywords: Pancreas, Adenocarcinoma, Clusterin, Survival

\section{Background}

Pancreatic cancer is a fatal disease with an annual incidence that approaches its mortality rate $[1,2]$, and the 5 year survival rate is about 5\% [3]. Pancreatic adenocarcinoma accounts for most pancreatic cancers, and lymph node metastasis is one of the most significant prognostic factors in pancreatic adenocarcinoma patients. However, the extent of lymph node dissection is highly dependent on the operator and the number of dissected nodes can be small, especially when malignancy is not suspected preoperatively. A new biological predictive marker is therefore needed to supplement lymph node status, which can also be used to evaluate the efficacy of adjuvant treatments.

Clusterin is ubiquitously expressed in al most all mammalian tissues and has been found in all human body

\footnotetext{
*Correspondence: 196087@inha.ac.kr

${ }^{3}$ Department of Surgery, Inha University School of Medicine, 7-206, 3-Ga

Sinheung-Dong, Jung-Gu, Incheon 400-711, Republic of Korea

Full list of author information is available at the end of the article
}

fluids analyzed [4]. Furthermore, clusterin is also known to be overexpressed in various cancer tissues, including pancreatic cancer [5]. However, the role played by clusterin in pancreatic cancer cells is still unclear, and its clinical significance has yet to be determined. There are two isoforms of clusterin identified, the secretory and the nuclear isoforms [6]. In the present study, we investigated relations between expression of the secretory isoform of clusterin and clinicopathologic parameters to assess its potential value as a prognostic indicator in pancreatic adenocarcinoma.

\section{Methods}

Pancreatic cancer samples

Pathologically proven pancreatic adenocarcinoma tissue samples were obtained from 52 consecutive patients who underwent surgical resection with radical intent in Inha University Hospital from July 1997 to June 2008. All samples were collected using protocols approved by 
the local Institutional Review Board, and informed consents were obtained from all the patients.

\section{Immunohistochemical analysis}

Imunohistochemical staining was performed as described previously [7]. All surgical specimens were fixed in 10\% formalin, embedded in paraffin, and consecutively sectioned at $5 \mu \mathrm{m}$. Most representative sections from each case were dewaxed in xylene and treated with $0.5 \%$ hydrogen peroxide in absolute methanol for 30 minutes to block endogenous peroxidase activity. The sections were then washed in PBS and blocked with normal horse serum for 30 minutes at room temperature. Each tissue section was incubated with goat anti-clusterin antibody (1:800; Santa Cruz Biotechnology, Santa Cruz, CA, USA) overnight at $4^{\circ} \mathrm{C}$, washed in $\mathrm{PBS}$, and incubated with biotinylated

Table 1 Correlations between clusterin expression and clinicopathologic parameters and univariate analysis of survival in pancreatic adenocarcinoma

\begin{tabular}{|c|c|c|c|c|c|}
\hline Parameter & Number of cases (\%) & $\begin{array}{l}\text { Clusterin expression } \\
\text { Clusterin-positive cases (\%) }\end{array}$ & $P$ value & $\begin{array}{l}\text { Survival analysis } \\
\text { Median survival (months) }\end{array}$ & $P$ value \\
\hline Overall & $52(100.0)$ & $17(32.7)$ & & 14.9 & \\
\hline Age & & & 0.780 & & 0.029 \\
\hline$\geq 65$ years & $35(67.3)$ & $11(31.4)$ & & 10.4 & \\
\hline$<65$ years & $17(32.7)$ & $6(35.3)$ & & 38.7 & \\
\hline Sex & & & 0.747 & & 0.792 \\
\hline Male & $37(71.2)$ & $13(35.1)$ & & 15.0 & \\
\hline Female & $15(28.8)$ & $4(26.7)$ & & 10.4 & \\
\hline Tumor size & & & 0.241 & & 0.075 \\
\hline$\leq 2 \mathrm{~cm}$ & $9(17.3)$ & $1(11.1)$ & & 35.4 & \\
\hline$>2 \mathrm{~cm}$ & $43(82.7)$ & $16(37.2)$ & & 14.7 & \\
\hline Location & & & 0.413 & & 0.648 \\
\hline Head & $44(84.6)$ & $13(29.5)$ & & 15.0 & \\
\hline Body/tail & $8(15.4)$ & $4(50.0)$ & & 9.9 & \\
\hline Pathologic grade & & & 0.711 & & 0.010 \\
\hline Well/moderately differentiated & $42(80.8)$ & $13(31.0)$ & & 15.9 & \\
\hline Poorly differentiated/anaplastic & $10(19.2)$ & $4(40.0)$ & & 3.1 & \\
\hline Perineural invasion & & & 0.042 & & 0.414 \\
\hline No & $8(15.4)$ & $0(0.0)$ & & 18.5 & \\
\hline Yes & $44(84.6)$ & $17(32.7)$ & & 11.5 & \\
\hline Lymphovascular invasion & & & 0.330 & & 0.055 \\
\hline No & $15(28.8)$ & $3(20.0)$ & & 39.6 & \\
\hline Yes & $37(71.2)$ & $14(37.8)$ & & 8.9 & \\
\hline Preoperative CEA (ng/ml) & & & 0.048 & & 0.787 \\
\hline$\leq 5$ & $32(69.6)$ & $8(25.0)$ & & 15.0 & \\
\hline$>5$ & $14(30.4)$ & $8(57.1)$ & & 14.7 & \\
\hline Preoperative CA19-9 (U/ml) & & & 1.000 & & 0.640 \\
\hline$\leq 37$ & 15 (33.3) & $5(33.3)$ & & 15.9 & \\
\hline$>37$ & $30(66.7)$ & $10(33.3)$ & & 16.5 & \\
\hline Lymph node metastasis & & & 0.006 & & 0.002 \\
\hline No & $16(31.4)$ & $1(6.3)$ & & 39.7 & \\
\hline Yes & $35(68.6)$ & $16(45.7)$ & & 9.9 & \\
\hline Clusterin expression & & & - & & 0.312 \\
\hline Negative & $35(67.3)$ & - & & 15.0 & \\
\hline Positive & $17(32.7)$ & - & & 14.9 & \\
\hline
\end{tabular}

CA19-9, carbohydrate antigen 19-9; CEA, carcinoembryonic antigen. 
anti-goat IgG and avidin-biotin complex (Vector Laboratories, Burlingame, CA, USA) as secondary antibody for 1 hour at room temperature. Sections were then developed using diaminobenzidine tetrahydrochloride solution (Sigma-Aldrich Corporation, St Louis, MO, USA) and counterstained with hematoxylin. Islet cells were used as internal positive controls. Any case showing focally or diffusely positive tumor cell cytoplasm was defined as clusterin-positive.

\section{Clinicopathologic data}

Medical records were reviewed retrospectively, and data were collected from a medical database. Survival data were extracted from the Korean MicroData Service System (Statistics Korea, Daejeon, Republic of Korea).

\section{Statistical analysis}

Statistical analysis was performed using SPSS for Windows version 12.0 (SPSS, Chicago, IL, USA). The chisquare test was used to examine the nature of the correlation between clusterin expression and clinicopathologic parameters. Survival rates were determined using the Kaplan-Meier method and survival differences were analyzed using the log-rank test. Cox regression was used to identify prognostic factors by multivariate analysis. $P<0.05$ was considered statistically significant.

\section{Results}

Demographic data and surgical results

There were 37 male and 15 female patients; a male to female ratio of 2.5:1. The median age was 68 years (range, 44 to 87 years). Tumors were located in the head of the pancreas in 44 cases and in the body and/or tail in eight cases (Table 1). All patients with a tumor in the head of the pancreas were managed by pancreaticoduodenectomy with or without gastric pylorus preservation, and the other eight patients were managed by distal pancreatectomy with splenectomy. One patient with a tumor involving the whole pancreas was managed using a combined procedure; the tumor was classified as a head lesion for the statistical analyses. Five patients succumbed to death within 30 days of surgery; an operative mortality of $9.6 \%$.

\section{Expression of clusterin in adenocarcinoma tissues}

Clusterin was expressed in 17 of the 52 (32.7\%) pancreatic adenocarcinoma samples. Clusterin was expressed in the cytoplasm of cancer cells in clusterin-positive cancers, (Figure 1a), and was expressed in normal islets but not in adenocarcinoma cells in clusterin-negative cancers (Figure 1b).

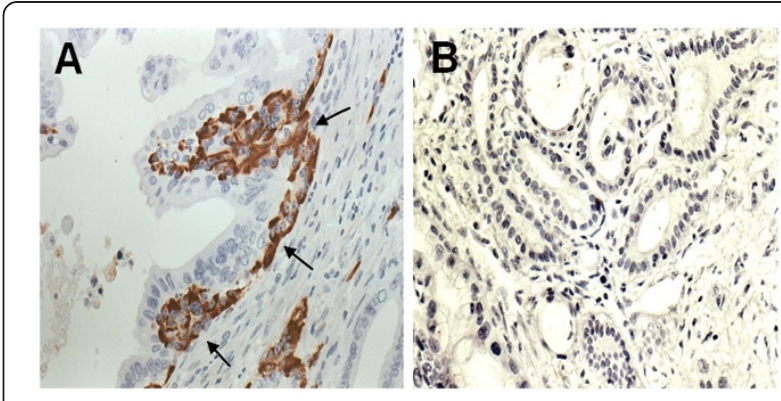

Figure 1 Clusterin expression in pancreatic adenocarcinoma. (A) Positive immunohistochemical staining for clusterin in the cytoplasm of ductal cancer cells near the basement membrane (arrows, $\times 400)$. (B) A clusterin-negative specimen $(\times 200)$.

\section{Clusterin expression and clinicopathologic characteristics}

Relations between clinicopathologic parameters and clusterin expression were investigated. Clusterin expression was found to be associated significantly with lymph node metastasis $(P=0.006)$, perineural invasion $(P=0.042)$ and elevated preoperative serum carcinoembryonic antigen level $(P=0.048)$, respectively (Table 1$)$.

\section{Survival analysis}

Overall median and 5-year survivals were 14.9 months and $16.6 \%$, respectively (Figure 2 ). The results of univariate analysis conducted to identify factors associated with survival are shown in Table 1 . Age $(P=0.029)$, pathologic grade $(P=0.010)$, and lymph node metastasis $(P=0.002)$ (Figure 3 ) were found to be significant prognostic factors. Clusterin manifestation was not found to be a significant prognostic indicator $(P=0.312$; Figure 4$)$, and lymphovascular invasion was only marginally significant $(P=0.055)$. Factors with $P<0.1$ and clusterin status were entered into the Cox regression multivariate analysis (Table 2). This

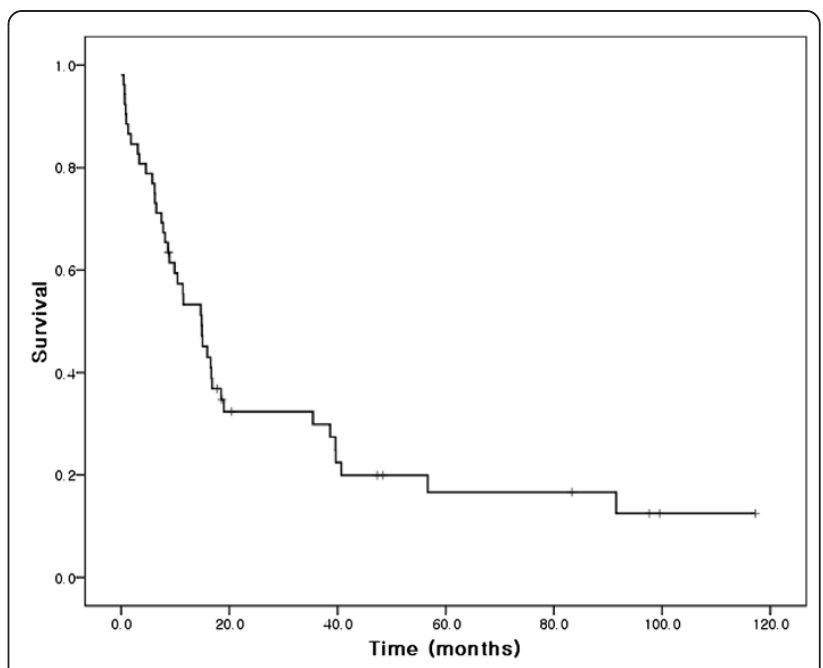

Figure 2 Overall survival curve for the 52 study subjects. 


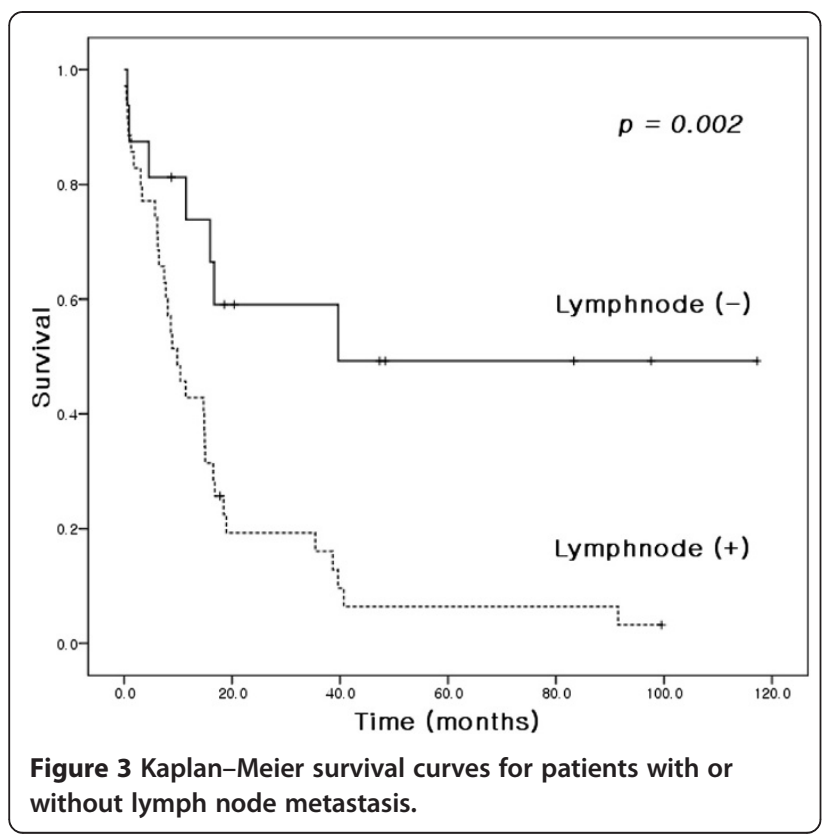

analysis showed that the pathologic grade and lymph node metastasis were significant prognostic factors.

\section{Discussion}

Despite recent diagnostic and management advances, pancreatic cancer remains a highly lethal disease $[1,2,8,9]$. The ability to predict prognosis provides an important means of determining management protocols and follow-up schedules. Of the many clinicopathologic parameters studied, lymph node metastasis has been most consistently associated with prognosis in pancreatic cancer [8,10-12]. Regarding biochemical markers of prognosis, virtually all potential molecules have been

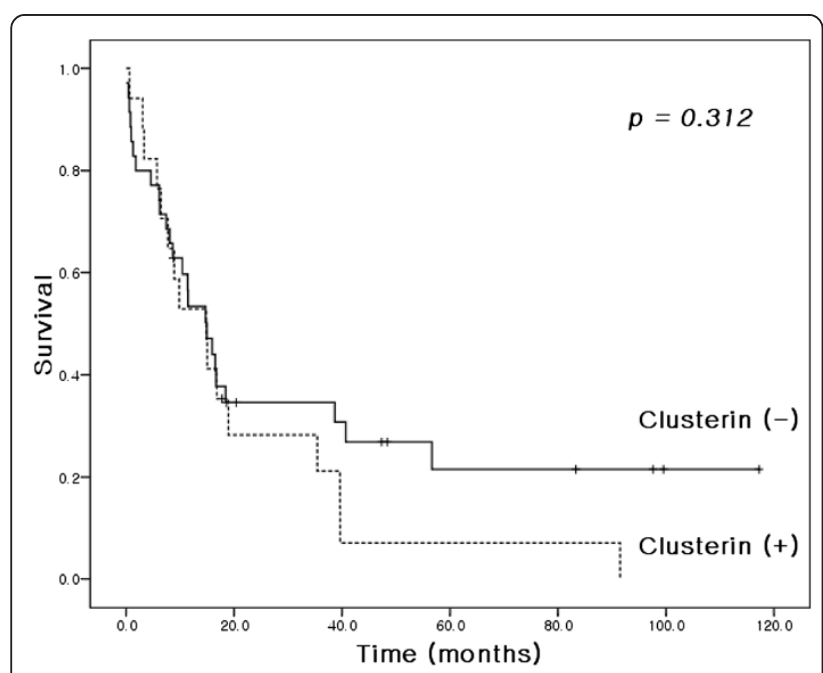

Figure 4 Kaplan-Meier survival curves by clusterin expressional status.
Table 2 Multivariate analysis of survival factors

\begin{tabular}{lllll}
\hline Factor & $\begin{array}{l}\text { Hazard } \\
\text { ratio }\end{array}$ & \multicolumn{2}{c}{$\mathbf{9 5 \% \text { confidence interval }}$} & $\boldsymbol{P}$ \\
& & Lower & Upper & value \\
\hline Age & 1.020 & 0.973 & 1.068 & 0.416 \\
Size & 1.728 & 0.559 & 5.337 & 0.342 \\
Pathologic grade & 3.462 & 1.251 & 9.579 & 0.017 \\
Lymphovascular invasion & 1.144 & 0.490 & 2.671 & 0.756 \\
Lymph node metastasis & 4.410 & 1.587 & 12.256 & 0.004 \\
Clusterin expression & 0.650 & 0.283 & 1.494 & 0.310 \\
\hline
\end{tabular}

tested. Recently, in an extensive review of the literature, Tonini and colleagues concluded that p16, matrix metalloproteinase-7, and vascular endothelial growth factor are probably useful indicators of prognosis [13].

Clusterin is a glycoprotein produced by a wide range of tissues and is present in most body fluids. In its secretory form, clusterin is believed to be involved in many physiologic processes, including apoptosis, morphologic transformation, and cell aggregation $[6,14]$. The clinical implications of clusterin expression in malignant diseases are controversial, and its contributions at the molecular level remain unclear. Clusterin overexpression has been reported to be marginally related to early recurrence and shorter survival in breast cancer, especially in early stage disease $[15,16]$, and has been shown to increase resistance to anti-estrogen hormonal therapy $[17,18]$. These results appear to be due to the association between clusterin expression in breast cancer tissues and lymph node metastasis and negativity for hormonal receptors $[19,20]$. Similarly, clusterin expression in prostate cancer has been correlated with the Gleason tumor grade [21], and is believed to compromise survival by inhibiting apoptosis after hormonal ablation therapy [22]. In a recent study, the possibility that clusterin expression may confer gemcitabine resistance in pancreatic cancer was suggested [23]. In ovarian carcinoma, clusterin overexpression has been shown to be correlated with tumor aggressiveness and/or to be a prognostic factor [24-26]. The results of the present study support the association of clusterin expression with lymph node metastasis and perineural invasion, and thus with aggressive tumor behavior of pancreatic adenocarcinoma. These findings are consistent with those of other studies performed on gastrointestinal adenocarcinomas, in which cytoplasmic clusterin expression was found to be associated with lymph node metastasis and significantly shorter survival in advanced gastric cancer [27], and colorectal cancer $[28,29]$. The exact mechanism of clusterin overexpression in enhancing cancer metastasis is still unclear. One of the plausible explanations is that clusterin may confer an anti-apoptotic effect on tumor cells once they are detached from the original site, and 
thus prolongs cell survival under unfavorable conditions in the metastatic process [30].

On the other hand, in an in vitro study of nonsmallcell lung cancer cell lines, clusterin overexpression was found to reduce chemosensitivity but indicated a favorable prognosis due to the inhibition of tumor cell migration [31]. Together with the finding that cytoplasmic clusterin expression is associated with chemoresistance [32], it is presumed that clusterin is basically cytoprotective and favorably affects prognosis in early stage lung cancer but compromises prognosis during late stage disease by conferring resistance to adjuvant radiotherapy and chemotherapy [33]. These seemingly disparate results may be due to a lack of knowledge regarding the causal relationship between clusterin expression and tumor cell apoptosis, which can affect patient survival.

Xie and colleagues recently reported associations between clusterin expression and various pancreatic pathologies including pancreas adenocarcinoma, and concluded that clusterin positivity is related to improved survival, at least by univariate analysis [5]. Their results contradict those of the present study with respect to the direction of the prognostic influence of clusterin expression. This disagreement may have been caused by the small number of cases involved in both studies and a shorter follow-up period in the former study, because in the present study the survival difference between clusterin-positive and clusterin-negative patients became apparent in survivors who had lived longer than 20 months, although the difference could not reach statistical significance.

To date, clusterin has not been found to be an independent prognostic factor for pancreatic adenocarcinoma. However, the results of the present study indicate that clusterin expression is strongly associated with lymph node metastasis, which is one of the most potent prognostic indicators. The impact of clusterin expression on survival can be too weak to be an independent prognostic factor, and further studies with a larger case volume may reveal the statistical significance. While extended lymphadenectomy did not show additional survival benefit [10], regional lymph node dissection still has a role in predicting the patient's prognosis [11]. There are also cases in which pancreas adenocarcinoma was an incidental finding [34], and the extent of lymph node dissection can be quite varied depending on the operator. Considering these circumstances, clusterin expression may provide an adjunctive means, with regard to the nodal status, in predicting survival, especially when the presence of malignancy is not suspected preoperatively. One of our patients had an occult cancer of the pancreatic head and underwent pancreaticoduodenectomy without lymph node dissection. In this case, the resected specimen was clusterin-negative, and the patient survived 57 months after surgery to succumb to nonsmall-cell lung cancer. The last abdominal computed tomography image in this case showed no evidence of pancreatic cancer recurrence at 47 months after pancreaticoduodenectomy.

\section{Conclusions}

Clusterin expression was not found to be an independent prognostic factor for pancreatic adenocarcinoma, although clusterin-negative patients tended to live longer. A further study on a larger patient population is needed to reexamine the prognostic value of clusterin expression and to identify the underlying mechanisms responsible. Nevertheless, the strong association between clusterin expression and lymph node metastasis suggests that clusterin can be used as an adjunct to lymph node positivity to predict survival in pancreatic cancer.

Abbreviations

PBS: phosphate-buffered saline.

Competing interests

The authors declare that they have no competing interests.

\section{Acknowledgements}

This work was supported by an Inha University Research Grant.

\section{Author details}

${ }^{1}$ Department of Hepatobiliary Surgery, The First Affiliated Hospital of Zhengzhou University, No. 100 of Science Road, Zhengzhou, Henan 450001, China. ${ }^{2}$ Department of Pathology, Inha University School of Medicine, 7-206, 3-Ga Sinheung-Dong, Jung-Gu, Incheon 400-711, Republic of Korea.

3Department of Surgery, Inha University School of Medicine, 7-206, 3-Ga Sinheung-Dong, Jung-Gu, Incheon 400-711, Republic of Korea. ${ }^{4}$ Department of Anatomy, Inha University School of Medicine, 7-206, 3-Ga Sinheung-Dong, Jung-Gu, Incheon 400-711, Republic of Korea.

\section{Authors' contributions}

All authors read and approved the final manuscript. JJ carried out the molecular studies. JMK interpreted the pathologic findings. YSH performed the operations. WPC carried out the data collection. KYL performed the operations and drafted the manuscript. SIA performed the operations. $\mathrm{KCH}$ performed the operations. ISP directed and interpreted the

immunohistochemical stain.

Received: 19 December 2011 Accepted: 18 June 2012

Published: 16 July 2012

\section{References}

1. Lockhart AC, Rothenberg ML, Berlin JD: Treatment for pancreatic cancer: current therapy and continued progress. Gastroenterology 2005, 128:1642-1654.

2. Siegel R, Ward E, Brawley O, Jemal A: Cancer statistics, 2011: the impact of eliminating socioeconomic and racial disparities on premature cancer deaths. CA Cancer J Clin 2011, 61:212-236.

3. Dunphy EP: Pancreatic cancer: a review and update. Clin J Oncol Nurs 2008, 12:735-741.

4. Jenne DE, Tschopp J: Clusterin: the intriguing guises of a widely expressed glycoprotein. Trends Biochem Sci 1992, 17:154-159.

5. Xie MJ, Motoo Y, Su SB, Mouri H, Ohtsubo K, Matsubara F, Sawabu N: Expression of clusterin in human pancreatic cancer. Pancreas 2002, 25:234-238.

6. Rosenberg ME, Silkensen J: Clusterin: physiologic and pathophysiologic considerations. Int J Biochem Cell Biol 1995, 27:633-645.

7. Min BH, Kim BM, Lee SH, Kang SW, Bendayan M, Park IS: Clusterin expression in the early process of pancreas regeneration in the pancreatectomized rat. J Histochem Cytochem 2003, 51:1355-1365. 
8. Cameron JL, Riall TS, Coleman J, Belcher KA: One thousand consecutive pancreaticoduodenectomies. Ann Surg 2006, 244:10-15.

9. Ozawa F, Friess H, Kunzli B, Shrikhande SV, Otani T, Makuuchi M, Buchler MW: Treatment of pancreatic cancer: the role of surgery. Dig Dis 2001, 19:47-56

10. Pavlidis TE, Pavlidis ET, Sakantamis AK: Current opinion on lymphadenectomy in pancreatic cancer surgery. Hepatobiliary Pancreat Dis Int 2011, 10:21-25

11. Sahin TT, Fujii T, Kanda M, Nagai S, Kodera Y, Kanzaki A, Yamamura K, Sugimoto H, Kasuya H, Nomoto S, Takeda S, Morita S, Nakao A: Prognostic implications of lymph node metastases in carcinoma of the body and tail of the pancreas. Pancreas 2011, 40:1029-1033.

12. Kanda M, Fujii T, Sahin TT, Kanzaki A, Nagai S, Yamada S, Sugimoto H, Nomoto S, Takeda S, Kodera Y, Morita S, Nakao A: Invasion of the splenic artery is a crucial prognostic factor in carcinoma of the body and tail of the pancreas. Ann Surg 2010, 251:483-487.

13. Tonini G, Pantano F, Vincenzi B, Gabbrielli A, Coppola R, Santini D: Molecular prognostic factors in patients with pancreatic cancer. Expert Opin Ther Targets 2007, 11:1553-1569.

14. Viard I, Wehrli P, Jornot L, Bullani R, Vechietti JL, Schifferli JA, Tschopp J, French LE: Clusterin gene expression mediates resistance to apoptotic cell death induced by heat shock and oxidative stress. $J$ Invest Dermatol 1999, 112:290-296.

15. Kruger S, Ola V, Fischer D, Feller AC, Friedrich M: Prognostic significance of clusterin immunoreactivity in breast cancer. Neoplasma 2007, 54: 46-50.

16. Yom CK, Woo HY, Min SY, Kang SY, Kim HS: Clusterin overexpression and relapse-free survival in breast cancer. Anticancer Res 2009, 29: 3909-3912.

17. Toffanin S, Daidone MG, Miodini P, De Cecco L, Gandellini P, Cappelletti V: Clusterin: a potential target for improving response to antiestrogens. Int J Oncol 2008, 33:791-798.

18. Flanagan L, Whyte L, Chatterjee N, Tenniswood M: Effects of clusterin overexpression on metastatic progression and therapy in breast cancer. BMC Cancer 2010, 10:107-120.

19. Redondo M, Villar E, Torres-Munoz J, Tellez T, Morell M, Petito CK. Overexpression of clusterin in human breast carcinoma. Am J Pathol 2000, 157:393-399.

20. Zhang S, Zhang D, Zhu Y, Guo H, Zhao X, Sun B: Clusterin expression and univariate analysis of overall survival in human breast cancer. Technol Cancer Res Treat 2006, 5:573-578.

21. Steinberg J, Oyasu R, Lang S, Sintich S, Rademaker A, Lee C, Kozlowski JM, Sensibar JA: Intracellular levels of SGP-2 (clusterin) correlate with tumor grade in prostate cancer. Clin Cancer Res 1997, 3:1707-1711.

22. July LV, Akbari M, Zellweger T, Jones EC, Goldenberg SL, Gleave ME: Clusterin expression is significantly enhanced in prostate cancer cells following androgen withdrawal therapy. Prostate 2002, 50:179-188.

23. Chen Q, Wang Z, Zhang K, Liu X, Cao W, Zhang L, Zhang S, Yan B, Wang Y, Xia C: Clusterin confers gemcitabine resistance in pancreatic cancer. World J Surg Oncol 2011, 24:59-66.

24. Xie D, Lau SH, Sham JS, Wu QL, Fang Y, Liang LZ, Che LH, Zeng YX, Guan $X Y$ : Up-regulated expression of cytoplasmic clusterin in human ovarian carcinoma. Cancer 2005, 103:277-283.

25. Partheen K, Levan K, Osterberg L, Claesson I, Fallenius G, Sundfeldt K, Horvath G: Four potential biomarkers as prognostic factors in stage III serous ovarian adenocarcinomas. Int J Cancer 2008, 123:2130-2137.

26. Yang GF, Li XM, Xie D: Overexpression of clusterin in ovarian cancer is correlated with impaired survival. Int J Gynecol Cancer 2009, 19:1342-1346.

27. Bi J, Guo AL, Lai YR, Li B, Zhong JM, Wu HQ, Xie Z, He YL, Lv ZL, Lau SH, Wang Q, Huang XH, Zhang $\amalg$, Wen JM, Guan XY: Overexpression of clusterin correlates with tumor progression, metastasis in gastric cancer: a study on tissue microarrays. Neoplasma 2010, 57:191-197.

28. Kevans D, Foley J, Tenniswood M, Sheahan K, Hyland J, O'Donoghue D, Mulcahy H, O'Sullivan J: High clusterin expression correlates with a poor outcome in stage II colorectal cancers. Cancer Epidemiol Biomarkers Prev 2009, 18:393-399.

29. Redondo M, Rodrigo I, Alcaide J, Tellez T, Roldan MJ, Funez R, Diaz-Martin A, Rueda A, Jimenez E: Clusterin expression is associated with decreased disease-free survival of patients with colorectal carcinomas. Histopathology 2010, 56:932-936.
30. Miyake H, Gleave ME, Arakawa S, Kamidono S, Hara I: Introducing the clusterin gene into human renal cell carcinoma cells enhances their metastatic potential. J Urol 2002, 167:2203-2208.

31. Cheng CY, Cherng SH, Wu WJ, Yang TY, Huang XY, Liao FT, Wu MF, Sheu GT: Regulation of chemosensitivity and migration by clusterin in non-small cell lung cancer cells. Cancer Chemother Pharmacol 2012, 69:145-154.

32. Li H, Liu S, Zhu X, Yang S, Xiang J, Chen H: Clusterin immunoexpression and its clinical significance in patients with non-small cell lung cancer. Lung 2010, 188:423-431.

33. Panico F, Rizzi F, Fabbri LM, Bettuzzi S, Luppi F: Clusterin (CLU) and lung cancer. Adv Cancer Res 2009, 105:63-76.

34. Sachs T, Pratt WB, Callery MP, Vollmer CM Jr: The incidental asymptomatic pancreatic lesion: nuisance or threat? J Gastrointest Surg 2009, 13: 405-415.

\section{doi:10.1186/1477-7819-10-146}

Cite this article as: Jin et al:: Clinical significance of clusterin expression in pancreatic adenocarcinoma. World Journal of Surgical Oncology 2012 $10: 146$

\section{Submit your next manuscript to BioMed Central and take full advantage of:}

- Convenient online submission

- Thorough peer review

- No space constraints or color figure charges

- Immediate publication on acceptance

- Inclusion in PubMed, CAS, Scopus and Google Scholar

- Research which is freely available for redistribution 